Meta

Journal des tradlucteurs

Translators' Journal

\title{
Translation and Editing
}

\section{Dale S. Cunningham}

Volume 16, numéro 3, septembre 1971

URI : https://id.erudit.org/iderudit/002443ar

DOI : https://doi.org/10.7202/002443ar

Aller au sommaire du numéro

Éditeur(s)

Les Presses de l'Université de Montréal

\section{ISSN}

0026-0452 (imprimé)

1492-1421 (numérique)

Découvrir la revue

Citer cet article

Cunningham, D. S. (1971). Translation and Editing. Meta, 16(3), 135-152.

https://doi.org/10.7202/002443ar d'utilisation que vous pouvez consulter en ligne.

https://apropos.erudit.org/fr/usagers/politique-dutilisation/ 


\section{TRANSLATION AND EDITING}

\section{INTRODUCTION *}

Utopian definitions of the translator generally envision a person who masters the target language faultlessly, is perfect in the source language, and has achieved stature among the specialists in the subject matter at hand. It would be a major task to cull the countless varieties of this definition from the literature of translation, so I must leave it to some industrious compiler to prove or refute what I suspect an examination of these collected definitions would reveal.

The first major finding of such a study, I believe, would emphasize the opposing viewpoints of the theorists who hold that the translator is above all a language specialist and those who praise subject-matter expertise as the ultimate criterion. The other major finding - since even a nodding acquaintance with the relevant literature immediately reveals the great variety occurring in such definitions - would of necessity go beyond a merely factual presentation of variants, analyze the reasons underlying the differences, and hopefully present conclusions eminently useful to the theory and practice of translation. In the absence of even a dissertation-level gathering of viewpoints accompanied by at least preliminary analysis, my suspicions about conclusions must be a tentative, highly simplified guess : The hedging, hair-splitting, and qualifying which now characterize definitions of the translator probably stem from a realization conscious or not - that extreme statement of the three elements can portray only a fabulous creature. As long as «human » can be used synonymously with «imperfect», we can hardly attribute to the translator a trinity of perfections when we wish to speak to and about the real translator living in the real world.

Editing is my topic, but it is not a new subject ${ }^{1}$, nor is it one which $\mathbf{I}$ wish

* Acknowledgement : I should like to thank my colleagues in translation and editing - Eva Reiff, Henry Fischbach, Kurt Gingold, and William Thompson - for having read an early draft of this paper and making many helpful suggestions. The final responsibility for errors of fact or opinion, of course, remains mine.

1. E. B. Kuz'mina, ed., Redaktor i perevod, Moscow, Izdatel'stvo "kniga », 1965. 
to enter without a digression to reveal my own viewpoints and warn the reader of my bias before examining editing as an essential part of the translation process - regardless of whether the editor is the translator himself, another translator, or even a non-translator.

\section{TOWARDS A DEFINITION OF THE TRANSLATOR}

In taking sides on the controversy of language mastery versus subject-matter expertise, $\mathrm{I}$ have considered elementary logic - that translation is a language art and service in the broadest sense, theory - that the science underlying translation is linguistics, and practice - that throughout my apprenticeship and in my present practice I have dealt with language, namely the embodiment of ideas and the expression of subject-matter rather than with actual areas of expertise itself. By the same token, to emphasize subject knowledge - at the expense of language or other knowledge underlying the translation process - is to restrict and confine what the translator is, does, and can do. Such an approach opens no intellectual vistas, limits new possibilities, and subordinates translation to other activities rather than enhancing it as the independent profession it should become.

Can this stress on language and linguistics be justified by more than purely subjective feelings? Philology - when defined as historical linguistics — cannot provide an answer and has done little for translation as a science or profession. However, while nineteenth century linguistics may have contributed little to translation outside of the field of lexicography ${ }^{2}$, modern structural or descriptive linguistics as developed from the work of de Saussure, the Prague School, Bloomfield, and others, has begun to be a major force. Of the several books ${ }^{3}$ directly applying linguistic principles to translation, that by the brilliant linguist Eugene A. Nida is particularly significant, even in the choice of a title : Towards a Science of Translation ${ }^{4}$. The knowledge symbolized in the vast bibliography of books and papers on machine translation ${ }^{5}$ has not yet been evaluated and interpreted for what may be the most significant benefit derived from these massive research efforts : a new awareness and understanding of natural language which

2. Unfortunately, most compilers of multilingual dictionaries have remained blissfully ignorant of the historical, exemplified approach to lexicography, so there are few translator tools that equal the excellence that Grimm, the Oxford English Dictionary, or the Merriam-Webster ( 3 rd edition) have achieved for single languages.

3. A. V. Federov, Vvedenie y teoryu perevoda, Moscow, Izdatel'stvo literatury ma inostrannykh yazykakh, 1958 ; I. I. Revzin and V. Yu. Rozentsveig, Osnovy obshchego mashinnogo perevoda, Moscow, Izdatel'stvo "Vysshaya shkola ", 1964 ; J. C. Catford, A Linguistic theory of Translation, London, Oxford University Press, 1965 ; and 0 . Kade, Zufall und Gesetzmässigkeit in der Ubersetzung (Beiheft I zur Zeitschrift Fremdsprachen), Leipzig, VEB Verlag Enzyklopädie, 1968.

4. E. A. Nida, Towards a Science of Transtation, Leiden, E. J. Brill, 1964. See also his Learning a Foreign Language, rev. ed., New York, Friendship Press, 1967, and Bible Translating, rev. ed., London, United Bible Societies, 1961. All are linguistically oriented and can be obtained through local Bible societies.

5. See E. Delavenay (K. Delavenay, trans.), An Introduction to Machine Translation, New York, Frederick A. Praeger Publishers, 1960 ; E. and K. Delavenay, Bibliography of Mechanical Translation, The Hague, Mouton, 1960; retrospective bibliographies in Current Research and Development in Scientific Documentation, No. 12 (= NSF-65-10), Washington (D. C.), National Science Foundation, 1965, which cumulates the bibliographies of Nos. 1-11, et seq., and current bibliographies in The Finite String, Newsletter of the Association for Computational Linguistics, Washington (D. C.), Center for Applied Linguistics; and T. A. Informations, Paris and University, Editions Klincksieck and University of Alabama Press. 
should eventually be accompanied by the application of this new knowledge in further developing translation theory and in improving human translation. It is especially enheartening to note that the ALPAC report, which sums up approximately a decade and a half of American research on machine translation, recommends specifically that further effort be expended for the study of the human translation process, emphasis on machine-aided translation and the "production of adequate reference works for the translator ${ }^{6} \gg$.

Help for translators and progress in translation theory can also derive from the use of modern linguistic techniques in studying human acquisition of language. There are more than practical advantages in knowing how to learn still another language (or about it) most efficiently for the purposes required (e.g., reading, speaking, translating); research on thought processes themselves may lead to greater theoretical understanding of the act of translation. For example, work by Noam Chomsky ${ }^{7}$ suggests, at a simplistic level of interpretation, that the thought processes involved in acquiring a language as a child are perhaps the most complicated that any human being experiences in life. Possibly this may explain why only a small percentage of all people ever learn to handle their native language with superior skill. In any case, it suggests that translation is not the easiest profession to which one can aspire and that the source and target-language abilities of a translator far overshadow the importance of subject-matter knowledge in the trinity of skills.

Acquisition of specialized knowledge is a process which begins relatively late in life - and only subsequent to the acquisition of at least one language! Furthermore, a certain portion of this effort represents the learning of vocabulary, jargon, or perhaps what could be best designated as the language (or sublanguage) of the specialized field.

The translator would then be defined — ideally - as a person who masters both target language and source language. Subject matter, if it need be mentioned at all, would be discussed only in terms of the language of any particular subject matter. And, when a translation approaching perfection is desired or required, it will readily be understood that editing is the medium through which a perfect or nearly perfect translator can be constructed - as a composite if such a person is not available as a single individual (and the rarity of their occurrence in our world is a well known phenomenon).

Many problems presently encountered by translators (and their clients) can readily be solved by an approach to translation viewing translation and editing as different, separate processes, and I suspect that many arguments recurring throughout the literature of translation would cease to have meaning if the subject had been approached within such a context. Leaving the types of

6. Automatic Language Processing Advisory Committee (ALPAC), Language and Machines, Washington (D. C.), National Academy of Sciences/National Research Council, Publication 1416, 1966

7. N. Chomsky, Syntactic Structures (Janua Linguarum, Series Minor 4), 1964 ; Current Issues in Linguistic Theory (Janua Linguarum, Series Minor 38), 1966; and Topics in the Theory of Generative Grammar (Janua Linguarum, Series Minor 56), 1966; Aspects of the Theory of Syntax, Cambridge, MIT Press, 1965; Cartesian Linguistics: A Chapter in the History of Rationalist Thought, New York, Harper \& Row, 1966; and with G. A. Miller, "Introduction to formal analysis of natural languages", in $R$. D. Luce, ed., Handbook of Mathematical Psychology, New York, Wiley, 1963, vol. II, p. 269-321. 
activities occurring in the translation process to the theory of translation, I shall now preceed to a description of the types of editing relevant to translation.

\section{CLASSES OF TRANSLATION EDITING}

Editing a translation is a process most easily surveyed when subdivided into a number of different activities. By partitioning the editorial act in this way, I do not mean to suggest categorically that editing must be carried out in such a manner and that each type must be done by a different person. However, I do feel that even the genius who approaches the Utopian ideal only occasionally performs the complex acts of translating and translation editing as a single simultaneous process. Translators who prefer doing everything themselves will probably work better if their translation is the result of two or more non-concurrent activities which have consciously different mental approaches and goals. For the translator whose profession is his livelihood, I feel that separation of translating and editing activities is an absolute necessity. Similarly, I should like to see the editing performed or assigned in such a way that a nearly perfect composite translator is produced by having a number of individuals work on the same translation.

A translation must first be compared with the original for completeness and sense. Omission of words, phrases, and even paragraphs is one of the most common errors I have encountered in examining translations. A comparative check for completeness can probably be carried out most efficiently by the same person who compares the translation with its original for sense, actual misunderstandings of the source language that distort meaning. Words such as «not», «in- », and « un- 》 have a habit of disappearing with consequent reversal of sense $^{8}$. Until translation theory has been perfected to a point which will allow more accurate prediction of where non-correspondence will occur between any pair of target and source languages, comparison editing is difficult to define in detail. The general instructions are clear, however. When efficiency is a goal, any editor should remember that superimposition of strictly personal preference is merely a waste of time (and often of emotion). Why change a perfectly possible, grammatically correct way of saying something?

Under the heading of subject-matter vocabulary, I see an editorial process which becomes necessary when the translator is not a native speaker of the sublanguage in the particular field or fields of specialization occurring in the original which is to be translated. By «native speaker», I mean a subject-matter expert as opposed to someone like a translator or editor who may or may not have acquired some knowledge of the vocabulary in a specialized area of human endeavor. «Expert» evokes the image of a scholar, advanced degrees, doctors or lawyers, but experts in subject-matter vocabulary can also be hairdressers, dancers, supermarket clerks, mechanics, and a wide variety of other non-academic individuals. It is the original document which determines who the subject-matter expert will be. It should be equally obvious that such experts can be monolingual and need no writing ability or other editorial skills. The monolingual (possibly

8. Lest the reader suspect that I have inspected solely work by rank amateurs, I call attention to some examples in Section 5 below. 
even illiterate) expert has to be helped by a translator or editor or both, a process which can occasionally demand special skills or training in linguistics ${ }^{9}$. Once again, I emphasize that a translator almost by definition should be presumed to have the intellectual capability of learning a new field of specialized activity singing or astrophysics - and how to manage its concepts, thought patterns, and language. Someone translating for the joy of it and in the service of art will even feel ethically obliged to do so. At the same time, however, the professional who earns his keep from translation will soon realize that adding new areas of subject-matter expertise is a luxury at odds with meeting deadlines and eating regularly.

Correct or even elegant target-language usage is the main objective of target-language editing, a second function being editorial styling. Styling is not only a matter of following the manual and having «PhD» or «Ph. D. » but not both, but also an attempt to achieve consistency in vocabulary and so on. Once again, the essential qualifications have nothing to do with translation. Writing ability and editorial training are the characteristics that count. Whether working with literary, scientific, specialized or popular subject matter, the editor must learn to suppress an urge to change for the sake of change - the overzealous corrector frequently introduces new errors.

Handy summary tags for these editorial processes are provided in Table 1 below. Concrete examples of translation editing in practice are given in the following section and should eliminate the need for further explanation.

TABLE 1

Categories of translation editing

\begin{tabular}{llll}
\hline I. TL-SL comparison & II. SM vocabulary & III. & TL editing \\
A. Completeness & A. Technical terminology & A. Elegance (correctness) \\
B. Sense & B. Technical usage & B. Style (consistency) \\
1. Distortion & & & $\begin{array}{l}\text { 1. Style manual } \\
\text { 2. Fine points }\end{array}$ \\
\hline
\end{tabular}

$\mathrm{TL}=$ target language; $\mathrm{SL}=$ source language; $\mathrm{SM}=$ subject matter.

\section{EXAMPLES OF TRANSLATION EDITING}

Once the definition of translator has been limited to language skills and the categories of editing outlined, we should look at a few concrete examples of how the translator as his own editor or the translator as the key individual in a team can actually function. Table 2 shows attributes of the ideal translator and of some typical skills of individuals who are more apt to exist in the world we know. It is discussed in more details below.

Human as it may be to want to do the whole job oneself, I think that this is expected or even required today only in the translation of poetry and other literature. Of course, there is a great deal of satisfaction in doing a job from start to finish, perhaps even in being truly Renaissance in spirit and proceeding to set the type and roll the presses, too. However, I often wonder if

9. Determining correct technical terms or usage is an activity akin to field linguistics in anthropology. Nida's book on foreign-language learning (see note 4 above) keeps in mind the missionary who can be faced with the problem of learning an unwritten language from the natives all on his own. It has an excellent bibliography. 


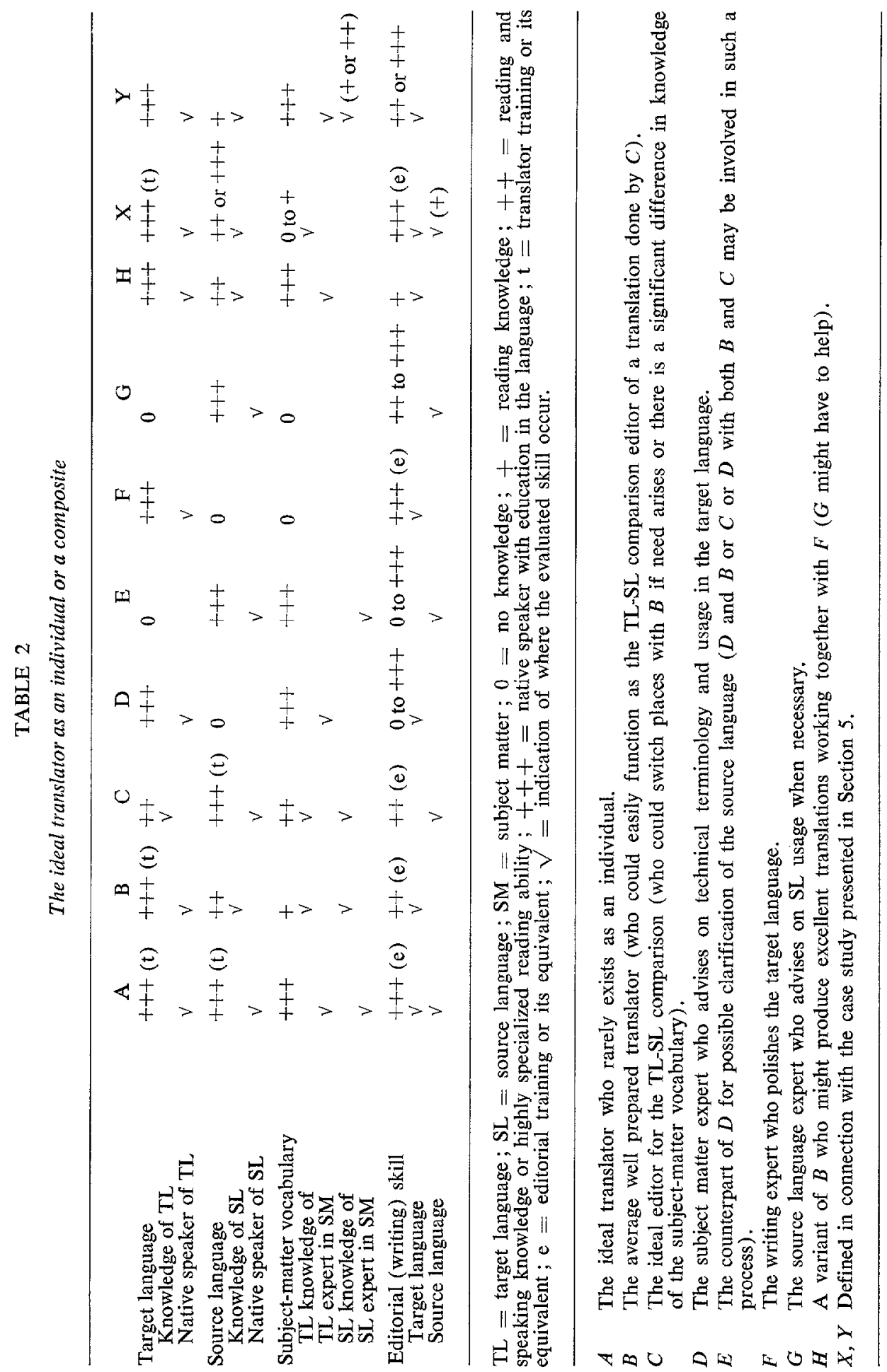


the original author, the translator, the publishers of both, the reading public, and even Art would not be better served by the literary equivalent of collaborations which have worked so well in scientific and literary fields. (All writing being a literary art, the postulation of a «scientific-technical » translator as opposed to the «literary » translator appears as false to me as the injection of « subjectmatter expertise $\gg$ into the definition of translator ${ }^{10}$.

No one can possibly know all the subspecializations of a subject, not to speak of larger, related fields. For example, the AMA style manual lists well over hundred "Classifications of Materials », most of which could be regarded as medical (sub) subspecializations ${ }^{11}$. Yet, the translator who has some training in techniques, good language skills, and some perseverance can do adequate work alone (at least for information purposes, if not for publication).

Emphasis should be on the language usage, naturally, not the actual field which is totally foreign to him. Unfortunately, illustration of this point has to be involved and technical ${ }^{12}$. Attempting to accomplish everything alone will result only in a lack of time in which to earn a living.

10. The best single exposition of this viewpoint with numerous examples of literature occurring in scientific papers or of the vocabulary of science, technology or other specialized fields in literary works is given by $\mathbf{I}$. J. Citroen, "The Myth of the Two Professions - Literary and Non-Literary Translation », Babel, XII, 4 (1966) : 181-188.

11. Division of Scientific Publications, Style Book and Editorial Manual, $2^{\text {nd }}$ ed., Chicago, The American Medical Association, 1963, p. 82-84.

12. I should like to present an example from my own experience. The translation assignment came from a large pharmaceutical company with an in-house staff of translators. While I had done many a translation falling into the "medical " category, this first paper in orthopedic surgery was in as different a field of human endeavor as was the mathematics of pre-stressed concrete at a later date. The German text was simple, straight-forward, and terse - perhaps the work of half an hour's translation time. However, an unknown term Varisationsosteotomie appeared at an obviously critical point : the title. The in-house translators had seen the word in previous work, but had been assured by the person who ordered the translation that «varisation osteotomy " was widely understood. Perhaps it was « translator instinct " that made me check further - not to speak of the fact that an in-house translator has a privileged personal relationship with the client, whereas the outsider must always guard against being classified as an "out-house" translator. In any case, when «varisation " did not appear in the second or third editions of the Webster's New International Dictionary, nor in any of three monolingual German medical dictionaries, nor in any of eight monolingual English medical dictionaries, nor in any of about a score of specialized scientific and medical multilingual dictionaries, my translator's conscience was really disturbed. Some twelve hours of research in journals and textbooks in the area of subject specialization proved that the Varisationsosteotomie was none other than a procedure known as « varus osteotomy " in England and America. The experience impressed me and was one of many which eventually led to the thoughts and viewpoints expressed in this paper.

There are also a couple of interesting sequels to the story. On the linguistic side, I once related the story to a group of friends at a translators' convention and then mentioned having noted the English pair « varus-vagus " which led me to postulate a German Vagisationsosteotomie. Lights flashed for one of my listeners, who had recently been stumped by just this word. A medium once existed through which this sort of nonrecorded knowledge can eventually find its way into the reference books : Translation Inquirer, New York, Metropolitan New York Chapter — American Medical Writers Association, with the support of The American Translators Association. Edited by the linguist, Dr. Alexander Gode, this periodical unfortunately ceased publication in 1969. The second experience was a fractured leg which eventually brought me into contact with a number of orthopedists. I found that there are at least six living Board-certified American specialists to whom the term "varisation " means nothing. The significance of this for me personally was more than the fact that the person advising the in-house translators was in error or lacked expertise ; the orthopedic surgeons I questioned were able to identify the operation involved after only a brief description. Thus, as interesting as my twelve-hour search was, the time could have been saved by using an expert. $\rightarrow$ 
Desertion of the profession does not provide the same answer to complaints about apparently low rates as does application of the correct editing processes. Some years after a personally instructive attempt to do everything on my own ${ }^{13}$, I was faced with the translation problems presented by a paper on the mathematics of pre-stressed concrete written in questionable French by a Polish scholar, a few minutes with a native speaker of French solved the purely linguistic problems left by the non-native author of the paper. One of my consultants with a doctorate in mechanical engineering helped with some technical terms, and (after the expert typist performed her usual quality work), the journal editor made a few changes of his preference and styled the translation for the typesetters. Not only was everyone involved happy with the prompt, high-quality results — we all got paid at very respectable rates for the time involved for our respective contributions.

In literature, where the technical term can be a problem at times too ${ }^{14}$, the same sort of collaboration could be helpful. For example - and I can only theorize at this point of my experience - if translating a play, I would search for an editor totally native to English and with the added dimension of experience in putting words onto the stage, or if translating a novel an editor who can recast a clumsy phrase, recognize and delete true Gallicisms, Germanicisms, or other non-native expressions caused by translator fatigue and inertia. At the same time, I would hope this person could leave really creative transmission of the foreign « feel $\gg$ into English (a famous example from the Bible : King of Kings ${ }^{15}$ ).

Combinations of language knowledge, subject knowledge, and specialized editorial and writing skills have been visualized in Table 2. Column $A$ shows the * perfect $»$ translator who rarely exists as an individual. At the same time, $A$ represents the skills which may be necessary to produce the «perfect 》 translation and is therefore the picture one will aim for in compiling a composite translator by using the skills of several people. It will readily be seen that two to four people may have to work on a translation in order to contribute a level of competence in each category equal to that called for under $A$.

Having such a chart before him, the individual translator can determine the people he needs to supply the skills he lacks - as long as he can be honest

Experiences such as this are a very rewarding part of the translator's work, and I confess to having experienced the same exhilaration in finding "varus osteotomy " as in achieving several lines of poetry in translation which satisfied me. However, the translation of poems is an extracurticular part of my profession, a part-time relaxation and welcome refuge from many species of documents which can cross the desk of a translator who has opened his mail box to serve the public : birth certificates, scientific and technical papers too poorly written and too poorly conceived to really merit being transformed into another language, credit reports from abroad, divorce decrees however spicy they may be, patents perpetually illustrating something or other in verbiage undulating laterally from left to right and possibly outweighing the exemplified embodiment accorded to the invention. Remuneration for a poem can be the satisfaction alone or come through unpaid publication making it available to others. On the other hand, when translation is one's life's work as well as one's life's play, even a triumph over the unrecorded technical term must result in bread - and Varisationsosteotomie required excessive mental effort and research as background for a half hour's translation which was only long enough to result in a professional remuneration for the half hour.

13. See note 12 above.

14. See note 10 above.

15. On the fascination of creative mistranslation, see the notice to the American Translators Association republished in Der Ubersetzer, V, 10 (October 1968) : 2 . 
and objective in evaluating his true competence in each category. For the agency or agent, one could visualize a punched-card or computerized record of available skills as an invaluable aid in assigning work.

It took considerable experimentation involving many attempts to achieve the mutual interaction of theory and practice before $\mathbf{I}$ arrived at this visualization of the composite "perfect » translator. With such a scheme, however, it is easy to see how a subject specialist, particularly in a field of exact science, can become extremely proficient in translating from a dozen or even two dozen languages in his area of specialization with very little outside help from other individuals. The more limited the field and the more objective the tradition of reporting results, the more limited the problems will be which are presented by source languages. It is also a concept of this type, whether or not expressed explicitly, which enables a poet like Robert Lowell to «translate » poetry with collaborators or trots from languages he does not know at all ${ }^{16}$.

Personal interest has led to further experimentation along these lines. University-level translator training is practically non-existent in America, so I hope the reader will forgive me a description of what more or less happened in my case, though it can be obtained formally now in Europe ${ }^{17}$. My academic training involved extensive study of three languages and literatures; it also provided the start of a reference library for these languages which now includes several thousand items. My interests later led to formal training in linguistics and private study of the literature of translation as a subject. In science, my preparation can best be described as a nodding liberal-arts sort of acquaintanceship. Finally, I had some helpful editors as a fledgling translator and, later, the privilege of collaborating with many specialists in writing on translation projects.

With this background and having satisfied some clients with translations from German and French, I was persuaded to give them work from Danish, Dutch, Norwegian, and Swedish. I accomplished this by collaborating with native speakers of these languages as informants. (In some cases, these were the very persons who had been doing unsatisfactory work caused by lack of translator training and practice, lack of English-language facility, lack of subject-matter knowledge, or other reasons.) The technique involved drawing on the knowledge of these people as living grammar books and dictionaries to supplement the printed references available and obtain a quick oral version. This was discussed as required, recast mentally or orally, and a version acceptable to both was dictated for later transcription. Everyone concerned has been satisfied by the pay and the results. The cost to the clients remained about the same, while the quality and the predictability of delivery dates were considerably improved.

Although the native speakers involved in these experiments spent less time, their remuneration improved when expressed as an hourly rate, and most have felt subjectively relieved from pressures (having my translator and Englishlanguage experience available instantly) and were more satisfied intellectually with

16. For other, widely varying views on the collaborative or trot technique, see also replies to the editorial questionnaire, "The State of Translation „, Delos, A Journal on and of Translation (National Translation Center), 2 (1968) : 29-67 and foldout.

17. W. Wilss, "The School of Translating and Interpreting of the University of Saarbrücken ", The Linguistic Reporter, XI, 4 (August 1969) : 1-4. 
the resultant product. In cases where extreme accuracy was required, a native speaker was also used for the editorial comparison for completeness and sense. Quite understandably, translation times vary from slightly less than normal for my own work alone to about double that time depending upon the education background and linguistic sensitivity of the native informant. Also, I have had little opportunty to extend the technique to non-Indoeuropean languages ${ }^{18}$.

It seems possible that such teamwork could make it feasible for far more people to consider literary translation as a full-time profession, and «minority literatures » might become a relative rarity. There is another very practical advantage in regarding translation as a series of activities defined as accurately and with as little overlap as possible : well delimited activities are measurable on an average over a period of time. Not all of the activities involved in the translation process are worth the same amount of remuneration. The professional earning his living through translation can earn professional remuneration only when his translation time is not diluted by relatively low-paying jobs such as getting the words onto paper physically, typing final copy, or counting words. For the individual translator, such a management tool provides a guide to those points at which the work should be turned over to others and even as to whether he is really competent and efficient enough to survive as a professional. In the translation agency, of course, the benefits will be obvious to those concerned with cost accounting and methods.

Having exemplified how translation can or could function combined with separate editorial activities, I will turn to a question in the following section which has only received brief attention : What degree of accuracy can be obtained by these methods?

\section{A CASE STUDY IN TRANSLATION ACCURACY}

The journal Lebende Sprachen (Langenscheidt) has presented many analytical studies of translations throughout its thirteen years of publication. It is interesting to note how many errors the individual translator can make, and in the case of the published translations, how little publishers must know about providing editorial assistance to their translators. Unfortunately, these studies have remained qualitative and not completely helpful. The majority of books analyzed in Lebende Sprachen have been works of literature, which is far more difficult to quantify - if such an attempt should be made at all ${ }^{19}$. After counting well over hundred changes I would make in a translation of Franz Kafka's short story Das Urteil ${ }^{20}$, I finally decided

18. A few words done here and there suggests that the reliability of such translation leaves something to be desired. For example, a colleague called one day with half a dozen words needed urgently in English. I happened to know a housewife who was native to this language, and my telephone call to her elicited the apparent nonsense "Time for sleeping as written on the card ". I was not overly enthusiastic about reporting this back to my friend but - eureka - the " context $"$ was the label on a bottle of pills, and the real translation probably "Take at bedtime as directed on the insert ". Our guess was passed on for what it was worth, and no money changed hands. I think we both felt that our translation services in this case had to be regarded in a class with " good advice".

19. An excellent successful qualitative study is N.-J. Kann, Ubersetzungsprobleme in den deutschen Ubersetzungen von drei anglo-amerikanischen Kurzgeschichten... (Mainzer Amerikanische Beiträge, Band 10), Munich, Max Hueber Verlag, 1968.

20. Willa and Edwin Muir, trans., The Judgement, New York, Schocken Books, 1948. 
that the number of errors seemed quite meaningless when dealing with an author whose every word counts toward the total interpretation. «You have a friend in St. Petersburg» appeared for «Sie haben keinen Freund in Petersburg», the father's nightgown was translated into a shirt, and one word - ambiguous in the original but central to at least one interpretation of the story ${ }^{21}$ — was translated with a total lack of ambiguity and without a footnote. It seemed impossible to make the translated version more worthless simply by enumerating and quantifying scores of other greater or lesser infidelities. Such studies do serve an important purpose, however, for they provide raw material for investigations of what kind of error is likely to occur in translation between any two languages. Such knowledge is very important in translator training and in pinpointing situations where the editor should be particularly alert. Specific studies along these lines are not known to me, but relevant work has been published ${ }^{22}$.

While quality is of great concern in any translation and to the community of translators ${ }^{23}$, it seems more probable that a quantitative study of translation accuracy would be most useful in scientific and technical matter. Carroll has conducted an experiment in the evaluation of translation quality ${ }^{24}$, but this method does not make quantitative expressions concerning the absolute accuracy of any particular translation.

Funds, materials, and personnel were not available for as scientifically objective a study as that by Carroll. However, a modest study with an attempt to be objective can be an adequate preliminary substitute. Once again, I will have to beg the reader's forbearance for my use of personal experience.

Table 2 includes two columns headed $X$ and $Y$, which represent selfevaluations by myself $(X)$ and a graduate mechanical engineer $(Y)$ whose dissertation and specialty were in the subject area of the technical paper selected for the study. This paper was one of a number which had been well received by the client, who subsequently requested more work and who had very few comments despite repeated requests for feedback.

The translation was supposed to be work that would receive the minimum ratings of 8 on the Carroll scales of intelligibility and informativeness ${ }^{25}$ while aiming for 9. The client was agreeable to this goal, and the fee was set accordingly. (The cost of a "perfect translation » was estimated to be approximately double that of a translation with Carroll ratings of 8 , perfection being defined as a

21. K. H. Ruhleder, "Franz Kafka's Das Urteil : An Interpretation», Monatshefte, 50 (1963) : 13-22.

22. J.-P. Vinay and J. Darbelnet, Stylistique comparée du français et de l'anglais; A. Malblanc, Stylistique comparée du français et de l'allemand, Paris, Didier, 1958 and 1961 respectively (vol, I and II of Bibliothèque de stylistique comparée). See also « Types of Errors Common in Machine Translation", Appendix 11 of the ALPAC report (see note 6$),$ p. 76-78, and the first reference in note 5 .

23. E. Cary and R. W. Jumpelt, eds., Quality in Translation, New York, Pergamon Press Book - The Macmillan Company, 1963.

24. J. B. Carroll, briefly summarized as Appendix 10 of the ALPAC report (see note 6), and later reported in full as « An Experiment in Evaluating the Quality of Translations», Mechanical Translation, IX, 3-4 (1966) : 55-66.

25. Ibid. 
product indistinguishable from a paper written by a native American author of equal caliber ${ }^{26}$.

It will be noted from Table 2 that $X$ and $Y$ lacked certain elements required for a «perfect» translator according to $A$. For example, there was no native speaker of the source language, no native expert in the subject matter. As a result, we were left with at least one question which could have used such a person (wouldn't a different subscript be preferable? - the author of the original paper being the best authority, of course, and the question really being one of subject-matter usage rather than of anything related to translation per se). On the other hand, it can also be seen that the composite translator $X Y$ was overqualified in some respects, particularly in native usage of the target language, a consequence of the subject expert's being exceptionally literate for an engineer and the author of several well written papers. This overqualification made it possible for the subject editor $(Y)$ to catch some minor misunderstandings of the source language which the translator $(X)$ had missed. (I suspect that the ideal addition to the composite translator in this instance would have been a native speaker of the source language used as the editor checking for completeness. My personal experience has been that when the same person performs the different activities particularly within a short period of time - errors caused for any reason whatsoever are far more likely to be overlooked. Thus, in the present case, errors occurred when I undertook comparison of source and target languages very shortly that after translation and again when the typist did her own proofreading with only a quick onceover by the translator. No one is perfect, however; one minor transcription error escaped me at least three times, the subject editor twice, and the typist of the final copy, as well.)

\section{Methods}

The paper concerned a highly technical subject : When the translation was dictated $(X)$, various points were marked for editorial consideration by the subject-matter expert $(Y)^{27}$. Following transcription, the original was checked and given to the subject editor $(Y)$, who then scanned the paper very superficially, changed or approved as translated the pinpointed words or phrases, and discussed some doubtful points with me $(X)$, whereupon the remaining editing jobs were done $(X)$.

26. It would be axiomatic that a client is entitled to receive fully accurate translation from a professional translator, without an additional fee. Much dissatisfaction arises because clients and translators do not discuss or properly consider what amount of adequacy or perfection is actually required. While it has been suggested that translator accreditation would solve this problem, elaborate procedures in medicine and law do not seem to have guaranteed the consumer will receive quality service [e.g., see "The Plight of the U.S. Patient », Time, 21 February 1969, p. 53-58, or M. Mayer, The Lawyers, New York, Harper \& Row (1967)].

27. Except when dictionaries or other resources are obviously inadequate, this process can be described only as "empirical translator instinct». In typing, the symbols used were "//" which meant that the subject editor should "check the immediately preceding word or sense group ». If the query involved a number of alternative words, a question to the editor, instructions, etc., this material was enclosed by $" / / \cdots$ and «-//». These symbols are easy to spot in scanning the paper and are not used for any other purpose in typing or printing. "Knowing when you don't know », must be part of the translation process, not of the editing activity, so even if my study of the phenomenon were fully formulated, it would be inapproptiate for inclusion in the present paper. 
Several weeks later, after the translation had been typed in final form, the subject expert was asked to study the translation in detail, changing whatever he considered necessary, the emphasis naturally being on subject-matter usage, vocabulary, and substance. He was also asked to do a sample rewrite of a paragraph from the introductory matter and one from the text as if the paper were to be published in an American journal. When doing this, the expert was treated as if he had no knowledge of the source language whatsoever and did not even have a copy of the original paper available to him.

\section{Summarized data}

The results of this study have been summarized in Table 3 . The completed translation contained slightly more than 4600 English words. The translation and original were compared on four separate occasions, and the correspondence can be considered as perfect as humanly possible. Dealing only with the English, the subject expert made a total of 102 changes ; in the course of categorizing and discussing the changes made, we discovered one further typographical error. The 103 changes involved a total of 269 words of the translation. (In all likelihood, additional inspection of the paper by translators, subject specialists, or editors would result in still more changes; perfection will probably continue to remain a quality which is difficult to define and agree upon - perhaps among experts in particular.)

The subject-matter expert noted that, « even with the changes I suggest, the result retains some flavor of the original language $»$. It also seems significant that he declined to revise the text as if it were to be published : \& I do not think that a polished rewriting of the text can be realized. I cannot quite put myself in the author's place and write in English just what he knows about [the subject]. I find myself writing what I know about it and then it is no longer the author's work. » (Letter to the author.)

TABLE 3

A case study in translation accuracy (number of English words translated: 4600 ; positions in text where changes were made : 103)

\begin{tabular}{lccc}
\hline Categories of changes made & $\begin{array}{c}\text { Number of } \\
\text { positions }\end{array}$ & $\begin{array}{c}\text { Words } \\
\text { involved }\end{array}$ & $\begin{array}{c}\text { Percentage of } \\
\text { words changed }\end{array}$ \\
\hline Minor translation errors & 2 & 4 & 0.00088 \\
Major translation eriors & 6 & 25 & 0.00543 \\
Typographical errors & 16 & 23 & 0.00500 \\
Technical terminology & 20 & 28 & 0.00609 \\
Personal preference & 46 & 173 & 0.03761 \\
\hline Improvement of original & 13 & 16 & 0.00348 \\
\hline
\end{tabular}

\section{Analysis of the changes}

Categorization of the changes made was the most difficult part of the study, especially when dealing with translation errors. Of the eight translation errors, only four required reference to the original text and the classification of errors as «major» or «minor» should have been four each instead of the six-two assignment finally decided upon. (The two errors where $« a$ and $b$ » should have been $« a$ or $b \gg$. 
One translation error requiring reference to the original involved an omission which may have occurred during dictation or which may have been committed by the typist. A second error definitely occurred in this way ; a syllable went unheard and « infinite » became « finite» - an error that should have been picked up in comparison editing. The two remaining errors not handled by the expert as if they were simply divergences from standard technical usage were very interesting from the viewpoint of the interaction of subject-matter substance, subject-matter vocabulary, and the translation process. The first of these errors hinged upon the fact that a word in the original can be translated by some twenty English terms. By using «behavior» rather than «distribution», I had thrown my expert reader off the track and caused miscomprehension in an entire passage in spite of the fact that these two words are so close in meaning when they occur in a scientific context that they can frequently be used interchangeably. This error was serious because it occurred at a point where the author was explaining what he was attempting in the paper; however, the error did not affect the substance of the paper and could not be regarded as critical in the same sense were the errors mentioned above in connection with the Kafka translation. The second error of this type was simpler. The source language word was amply documented in very reliable technical dictionaries, but it had not been used in any of these usual senses. It is interesting to note how specialized experience had to be combined with translating techniques in order to solve the problem. In retrospect, I can see some linguistic clues that should have let me to question this word and pinpoint it for approval by the subject expert; however, there is nothing in the text to suggest that the dictionaries I relied upon were incomplete in this case. Likewise, as good a command of the source language as the subject editor happens to have in this case, the reference tools he has available would not have helped, although it is possible that some of mine would have. Alone, neither of us would have been able to solve the problem, not efficiently at any rate. Once the problem was recognized, however, it was a simple matter, after the dictionary information was rejected as not helpful, for me to analyze the word and describe possible meanings starting from literal uses. The subject expert then saw how this was related to the actual machine and described what was actually meant, whereupon I was able to suggest a single word suitable in this context.

A total of thirteen changes were suggested by the subject expert which were categorized as improvements on the original document. Here are some examples : The numeral $\& 1 \gg$ in an equation was omitted and the equation defined in the text as «per unit depth ». In another instance, a more internationally acceptable subscript was suggested. A number of unnecessary signs were omitted from equations, and five typographical errors were discovered, one of which resulted in considerable confusion as to which of two quantities was indicated by $\ll$ ». The existence of imperfections in the original from which one works brings up interesting questions : Should the perfect translation merely translate errors? Should errors be corrected silently? I think that the answers depend on the type of material being translated and on the purpose of the translation ; in any case, the questions are worthy of discussion. Here, however, I present merely my 
pragmatic decisions. When dealing with scientific and technical material, typographical errors are corrected with comment as long as there is no doubt (the domain of the subject-matter expert!) that the error is indeed merely typographical. (In some types of patent translation, however, it can be helpful to the user if even this type of error is called to his attention.) Other errors or divergences from accepted usage are always handled by editor's or translator's notes so that the reader of the translation can have no doubt as to how something was expressed in the original.

All but two of the typographical errors discovered involved mistakes of a single character. The other two were words typed twice due to some distraction that occurred in the course of typing. An IBM advertisement claims that the average typist makes an error every 75 to 125 words; thus, only half as many errors as would ordinarily be expected were actually found ( 23 as opposed to 46 ). However, even though the typist was above average, I felt that introducing an additional proofreading process could eliminate most or all of these errors in the future.

The next category contained changes which resulted in minor improvements to the technical terminology. I am sure that other evaluators of the translation might assign some of the changes included in this category as errors or conversely, as mere personal preference of the subject-matter expert. In order to permit the reader to judge for himself, however, a few samples are presented from this category.

\section{Translation}

averaged through the cross section at given values

heat conductivity

integration according to

the subscript characterizes

by the roundings

can be integrated closed

pressure on the distance traversed

\section{Changed to}

over
for
thermal
with respect to
denotes
by rounding
in closed form
over

The largest category of all is that called «personal preference ». Nearly half of the points at which the text was changed are included in this group, and the total number of words involved was nearly double that of all other categories involved. It is typical of this category that the meaning was not changed in any way even though the verbal expression was. In cases where meaning had altered in some way, the change was assigned to the category of improved technical terminology if the alteration was within the range of meanings offered by the original text, to the error category if a mistranslation was involved. A large number of the changes in the personal preference category involved rearrangement of sentence elements. (Example : "From equations (15) and (8) through (11), it follows in addition with $x=y$ that $A=B \gg$ was changed to read as follows : "With $x=y$ in addition, it follows from equations [...] that $A=B$.») While I feel the new version considerably improves the readability of a translation which was no doubt guided by inertial forces from the source language, such changes are not really necessary when the translation is not intended for publication and 
will be read or used by only a small number of readers. Further examples of changes made due to editorial preference can be seen below :

\section{Translation}

before the end of

does not become unambiguous

becomes that much greater, the more

up to the end of

of which use is made

a high degree of effeciency

occur more favorably

calculation by the method

\section{Changed to}

prior to
is ambiguous
increases as
throughout
used
high efficiency
be more favorable
the method

Thus, in addition to personal preference involving sentence rearrangement, there is a subcategory which consisted of substituting more concise but equivalent expressions. The final subdivision of editorial preference also provided an indicator of the subject editor's superior writing ability; while everything in the original was reflected in the translation, it was obvious to him (and to the translator) that a certain amount of this was excess verbiage. The text was considerably improved when numerous phrases were omitted : "when this was done», "in the course of this », « anyway», and so on. A convenient label for this type of change would be $"$ concise writing by omission $»$.

\section{Results}

As a result of this study, it was decided that all further work would be inspected in its entirety by the subject-matter expert in order to insure an almost perfect translation. Furthermore, it was possible to evolve a refinement in translation procedures which are equally applicable to literary or non-literary work. This step-by-step analysis is reported below.

\section{DISCUSSION AND CONCLUSIONS}

If translating is defined solely in terms of linguistic activity, it becomes a simple matter to separate translating from various editorial functions and thereby describe the creation of a «perfect 》 translation. Since this approach to translation does not require that the translator be a perfect translator, many of the arguments and disagreements found throughout the literature of translation (which can engender a great deal of personal emotion ${ }^{28}$ and occasionally cause chaos at translator conventions) can be readily resolved. Furthermore, the translator who defines himself in terms of someone performing a purely linguistic activity is apt to consider himself a professional far more easily than is presently the case the unprofessional remuneration of many translators is a constant theme at translator meetings and is even documented in the literature ${ }^{29}$. Thus, defining

28. B. Bierman, "On Translation : Comment, Dissent and Assent ", American Translator, II, 3 (October 1968) : 1-5.

29. The complaints of the translator may be akin to those of the "poor farmer » on one hand, and with more justice because the rest of society generally neglects translators on the other hand. The translator of scientific material rarely gets his name on his work, and when the translator of literature does, his efforts are rarely assessed and evaluated by reviewers as it should be - see $\mathrm{H}$. Briffault, "The Plight of the Literary Translator, Especially in the U.S.A. », Babel, X, 1 (1964) : 12-14, for a poignant expression of this. 
translation as an activity involving language can hasten the professionalization of translators, result in the production of quality work.

As a combination of translating and editing functions, the production of a translation can be viewed as occurring in four distinct processes as outlined in Table 4.

TABLE 4

Steps in the translating-editing process

1. Translation

Conversion of the source language to the target language

3. Subject-matter editing

A. Checking for correctness of technical terms

B. Checking for correctness or usage in a broader sense

C. Checking for correctness of subject matter sense
2. Comparison editing

A. Checking for completeness at all levels

B. Checking for fidelity

4. Translation editing

A. Checking for correct usage of the target language

B. Checking for consistency of typographical style

C. Checking for consistency of thought (similar to $\mathrm{C}$ under 3 )

Nevertheless, it is an obvious fact that only relatively few people earn their living solely from translation. Of the relatively few translators of literature who do little or nothing else, all but one of my acquaintance report incomes of less than a professional level. One should also note the relatively large percentage of husband-wife teams that are translating literature - a phenomenon suggesting that two people are required for a family income. Note also the number of American literary translators living abroad - perhaps with the need to take advantage of increased purchasing power. Possibly a similar cause underlies the number of women who are literary translators - which suggests that in many cases they did not have to support themselves by their literary translation [it has been suggested that translation in any form is ideally suited for women, H. Fischbach, "Translating, an Ideal Profession for Women », Journal des Traducteurs/ Translators' Journal, IX, 1 (January-March 1964) : 3-10]. Finally, one is confronted with the large number of translations which have required subsidy in one form or another - note the increasing involvement of university presses in the publication of translations or the fact that the Ford Foundation felt it worthwhile to fund a National Translation Center.

In government and industry, most full-time employees seem - as far as I am able to judge from personal acquaintanceships - to receive salaries on a truly professional level only when the duties include administrative assignments and, particularly in government, when the job title is not simply "translator". And only a handful of freelancers earn professional remuneration as independent individuals.

This subject deserves separate consideration at greater length, but I suspect that the causes are manifold. First of all, no professional association of translators anywhere in the world, to my knowledge, pays more than lip service to the fact that translation is irrefutably a unity that cannot be split into "literary " and " non-literary * activity (see note 10 above). The result is that every such society is concerned predominantly either with translation of literary matter or with the translation of non-literary material. A cause for this may lie in non-recognition of the principle discussed in the present paper. Most people writing on the subject of translation are consequently unable to speak to both groups simultaneously, and there is a near total lack of communication or fruitful interaction between the interest groups which do not seem to realize that they are doing the same thing. Secondly, many low salaries (as in the case of teachers) are simply a reflection of actual competence. I am no longer astonished by self-styled translators who readily demonstrate that : 1) they have an imperfect knowledge of both source and target language, 2) they have had very little formal language training, particularly in linguistics, 3 ) they did not attend a school of translation, which are admittedly scarce 
The actual stages might be somewhat like this : translating and pinpointing spots of particular doubt (dictation), checking the transcription, preparing the manuscript for the subject expert, comparison editing, editing by the subjectmatter expert, possible expert-translator interaction, possible consultation with experts in the source (or target) language or the subject-matter vocabulary in the source language, correction of target-language usage (which could precede editing by the expert or even comparison editing), editing for typographical style and stylistic consistency, final typing and proofreading. Use of a different person at each step would involve ten or more people, each of whom would be expected to be highly skilled in his particular function. While it is highly unlikely that a single individual can efficiently perform all these activities with equal skill based on experience and training, nothing exists in this theoretical approach to translation requiring the job to be split among so many people. In practice, this approach will aid the translator in assessing his own abilities, deciding at which stage or stages he needs outside assistance, and knowing when such outside help is basically less expensive and more efficient than his time as a translator.

Dale S. Cunningham

in the United States, 4) they failed to provide themselves with the equivalent of formal training through thorough knowledge of the literature of translation, and 5) most importantly, they neglected to undergo any sort of apprenticeship. What does astonish me is that such people expect to be paid anything for their services. Third, many underpaid translators have simply failed to make the necessary capital investment in translator's tools such as dictionaries. How can they expect to approach competence if the reference works are not on hand to help them cope with the numerous specialized vocabularies that can occur in a single original ? The final reason I shall list on the debit side of the translator is perhaps the only one unrelated to the principle of regarding translation as language activity : the refusal of the translator to mechanize or keep up with technology - typing is faster than writing, dictation faster than typing, and so on.

It would be unfair to place all the blame on the translator, of course. A handful of translators do as well as physicians or lawyers, by translating science and technology, and Robert Addis has suggested ["A Radical Thought", American Translator, II, 4 (December 1968) : 13-14.] that good translators will move where the money is : "Has English-speaking society ever been willing to pay for a good literary translation? The instances must surely be rare. It is cheaper, of course, to lament reverently that Racine, Goethe, Pushkin and the rest are untranslatable (an expensive economy, I think). " 